\title{
Impact of Coronavirus Disease on Nigeria Socio-Economic Development and Education Sector Response
}

\author{
Adebiyi David Shofoyeke ${ }^{1^{*}} \quad$ Adetunji Stephen Shofoyeke ${ }^{1,2}$ \\ 1. National Institute for Educational Planning and Administration, P.M.B. 562, Ondo, Ondo State, Nigeria \\ 2. Federal Capital Territory Universal basic Education Board,Garki Area 2, Abuja, Nigeria
}

\begin{abstract}
Coronavirus disease broke out in December 2019 in Wuham, China. It was then thought the disease was one of the viral diseases affecting China hence "China disease" and little did any know that it soon become a global disease (pandemic) that would shake the entire world. Thus, the disease has had debilitating impact on people and the negative effects on economic well-being of nations, health expenditure, household incomes and education are unquantifiable. The situation was compounded by government's measures of the lockdown, restrictions on internal and international travels, boarder closures, and closure of schools for almost six months which is the longest closure in the history of Nigeria amongst others to curtail the spread. This paper therefore examined the impact of the pandemic on Nigeria socio-economic development and education sector response. Based on findings and observations, the paper recommends that governments, parents, School Based Management Committees should support the schools with facilities to observe the safety measures and Covid-19 protocols since there is no end to the spread of the disease yet while permanent drug and vaccine discovered are hitherto not circulated around the world.
\end{abstract}

Keywords: Impact, Coronavirus, Socio-economic, Development, Education, Response

DOI: $10.7176 / \mathrm{JEP} / 12-6-08$

Publication date: February $28^{\text {th }} 2021$

\section{Introduction}

The coronavirus disease was first identified in December 2019 in Wuhan, the Capital of China's Hubei province. It was then thought that the disease was one of the viral diseases affecting China hence "China disease" and little did any know that it soon become a global disease (pandemic) that would shake the entire world. Since its emergency and spread, coronavirus disease (COVID-19) has become one of the most serious health problems in the world. It is the most life-threatening disease in the world and has led to the death of young and old. It is no respecter of age, education, race, culture, education status of a country. Analysts have described Covid-19 as a symbol of global crisis, public health problem, developmental crisis, economic ordeal, and challenges to human life. Its debilitating impact on people and negative effects on economic well-being of nation, health expenditure and household incomes are unquantifiable. However, according to Nigeria Centre for Disease Control (NCDC) the first index case in Nigeria was recorded in 3rd March, 2020 and by the $27^{\text {th }}$ January, 2021, the figure of confirmed cases has reached 126,160 with 1,544 deaths.

Center for Study of the Economics of Africa (CSEA, 2020) describes developing economics as sliding into a downturn as global coronavirus outbreaks put severe pressure on the economy. Specifically, in Nigeria, the emergency of COVID-19 and its increasing incidence has called for drastic review and changes in the earlier revenue expectations and fiscal projections. Also, social life of people has been drastically reduced, exposed to attack from individuals and groups of people because of policy of government to contain the spread of coronavirus disease (COVID-19).

Local and international news are dominated by trend of coronavirus pandemic, its effects, and various measures undertaken by countries to overcome the effects of the pandemic. This therefore underscores the need to examine the history, mode of transmission, trend, impact on Nigeria socio-economic development, education sector response to combat the spread of the pandemic with a view to draw recommendations for improvement.

\section{History and trend}

There have been different infectious diseases that threatened human existence across the globe. These diseases include but not limited to cholera bubonic plague, smallpox, HIV and influenza. They were regarded as pandemic because the outbreak cut across international borders and impact on human health, social and economic activities. The trend of impact of human life varies before their vaccines were discovered. Anderson (2009) in Ochmann and Roser (2012) suggests that in the last hundred years of its existence smallpox killed at least half a billion people. Similarly, the Spanish virus/flu in 1918 claimed over 10 million lives. According to Bongaarts, Francois and Patrick (2009), a cumulative total of 24 million people died from AIDS between 1980 and 2007, and by 2030 this total is projected to reach 75 million. Ebola, Zika and Severe Acute Respiratory Syndrome (SARS) are other viruses in recent years that have their toll on human health, social and economic activities but eventually faded out. 
Coronavirus disease is an infectious disease caused by severe acute respiratory syndrome coronavirus 2 $\left(\mathrm{SARS}-\mathrm{COV}_{2}\right.$ ). The World Health Organization (WHO) announced in February, 2020 that COVID-19 is the official name of the disease. The name had been chosen to avoid references to a specific geographical location, animal, species or group of people in line with international recommendations for naming aimed at preventing stigmatization.

According to Ahmet Riza Sahin et all (2020) in Auwal, Shehu and Galadima, (2020), in December 2019, many cases of pneumonia around Wuhan city were reported and findings showed that Huanan Seafood Market was the origin. Thus, the first case of COVID-19 epidemic was discovered with inexplicable pneumonia on December 12, 2019. From this report, the Municipal Health and Health Commission rapidly starting the pursuit concerning South China Seafood City where twenty-seven (27) cases were found, of which seven were in genuine condition while the rest of the cases discovered steady and controllable (Wuhan City Health Committee, 2019). On 9 January 2020, China CDC reported that a novel coronavirus (SARS-CoV-2) had been recognized as the causative specialist for 15 of the 59 pneumonia cases. Medical studies showed that the common history of high-risk animal contact of the viral pneumonia patients strengthened the prospect of infection transmitted from animals to human beings. Studies have also shown that the original source of the COVID-19 is from the animal and recently the virus is spreading from human to human (European Centre for Disease Prevention and Control, 2020 in Hassan, 2020). The disease (COVID-19) has since spread globally, resulting in the on-going crisis in the world and hence it was declared to be Public Health emergency of international concern and recognized as a pandemic on 11th of March, 2020 (WHO, 2020); Center for System Science and Engineering, (CSSE, 2020).

According to Worldometer as at May 03, 2020, 23:58 GMT 212 countries and Territories around the world have reported a total of 3,562,426 confirmed cases of coronavirus and a death toll of 248,101 since first patient of COVID-19 showed symptoms in Wuhan, China. As at 26th October, 2020, the figures rose to 43,629,114 confirmed cases, 1,162,522 deaths and 32,065,694 recoveries. These figures according to WHO again rose to $54,771,888$ confirmed cases including 1,324,249 deaths as at 17th November, 2020. Further to this, as at last update in January 28, 2021, 12.54 GMT, Worldometers reported that the global confirmed cases was $101,538,022$ comprising 2,186,749 deaths, 73,451,313 recovery and 25,896,992 active cases. This indicates that the number of confirmed cases, deaths and recoveries increased on daily basis. Thus, between November 17, 2020 and January 28, 2021, a period of 72 days, total confirmed cases increased by $46,766,134$ or $85.38 \%$ while death increased by 862,500 or $65.13 \%$. This indicates that the rate of spread is higher in the second wave which has been described as deadlier.

In Nigeria, the COVID-19 case was reported when an infected Italian citizen who came in contact with a Nigerian citizen who was infected with the Coronavirus. The Coronavirus spread to other citizens in Lagos and to other States in Nigeria. According to the Nigeria Centre for Disease Control (NCDC), number of confirmed cases rose from one in March 03, 2020 when the first index case was reported to 131 confirmed cases with 2 deaths by March 30th, 2020 and further rose to 873 confirmed cases with 28 deaths by April 22nd, 2020. As at May 05th the figure short up to 2,558 confirmed cases with 87 deaths and 400 recoveries which surged to 4,151 confirmed cases with 128 deaths and 745 recoveries on May 09th, 2020. The numbers that were confirmed positively daily increased leading to increase in total number. Thus, as December 25th, 2020,81,963 cases had been confirmed out of which 61,337 were discharged and 1,163 deaths recorded in the 36 states and the Federal Capital Territory (Oyekanmi, 2020).

On December 25th, 2020, Nigeria Centre for Disease Control (NCDC) recorded 1,041 new cases in 23 states which bring the latest figures by states as follows: Lagos total confirmed cases to 22,562, followed by FCT (6,385), Plateau (3,724), Oyo (3,693), Rivers $(2,916)$, Kaduna $(2,778)$, Edo $(2,690)$, Ogun $(2,103)$, Delta $(1,823)$, Kano (1,768), Ondo (1,722), Enugu (1,332), Kwara (1,088), Ebonyi (1,055), Katsina (965), Osun (942), Gombe (938). Abia (926), Bauchi (750), and Borno (745). Imo State has recorded 648 cases, Benue (493), Nasarawa (485), Bayelsa (426), Ekiti (346), Jigawa (325), Akwa Ibom (319), Niger (286), Anambra (285), Adamawa (261), Sokoto (165), Taraba (155), Kebbi (93), Yobe (92), Cross River (89), Zamfara (79), while Kogi state has recorded 5 cases only. This indicates that all states in Nigeria are affected by the pandemic but the prevalence varies. Lagos state has $34.5 \%$ of the total number of confirmed cases is the highest while kogi state has the least $(0.008 \%)$. It further shows that the impact on the states differs. According to the Presidential Task Force on COVID-19, the pandemic affected mostly group of people in their productive ages, which one can found in any society or community and this age-group range from 31-60 year.

The Nigeria Centre for Disease Control on January 27, 2021, reported COVID-19 update as follows: total confirmed cases - 126,160; Total number discharged- 100,365 and total deaths- 1,544. This shows that the spread of the disease increased as follows within a period of about one month (December 25, 2020 and January 27, 2021): Confirmed cased- 44,197 or 53.92\%; Discharged - 39,028 or 63.63\% and Deaths- 381 or $32.76 \%$. All states except Kogi have experienced increases in confirmed cases, number discharged and deaths. The total number of confirmed cases in Nigeria has made the country to rank $75^{\text {th }}$ position in the world, fourth in Africa and first in West Africa. Worldometers (2021) data of COVID-19 show that confirmed cases in South Africa, 
Egypt and Ethiopia are 1,430,648; 468,383 and 135,045 respectively and these make them rank first, second and third in Africa. With the raising confirmed cases of COVID-19 and the resulting deaths in Nigeria, the need to intensify more proactive measures becomes imperative.

Table 1: Monthly cumulative increase in number of COVID-19 confirmed cases and percentage (\%)

\begin{tabular}{|l|l|l|l|}
\hline Date (Month) & Number of confirmed cases & Monthly increase in confirmed cases & Percentage $(\%)$ increase \\
\hline March 3 & 1 & - & - \\
\hline March 31 & 135 & 134 & $13,400.0$ \\
\hline April 30 & 1,932 & 1,797 & $1,331.0$ \\
\hline May 31 & 10,162 & 8,230 & 426.0 \\
\hline June 30 & 25,694 & 15,532 & 153.0 \\
\hline July 31 & 43,151 & 17,457 & 68.0 \\
\hline August 31 & 54,008 & 10,857 & 20.0 \\
\hline September 30 & 58,848 & 4,840 & 9.0 \\
\hline October 31 & 62,691 & 3,843 & 6.5 \\
\hline November 30 & 67,557 & 4,866 & 7.8 \\
\hline December 25 & 81,963 & 14,406 & 21.3 \\
\hline January 27 & 126,160 & 44,197 & 53.9 \\
\hline
\end{tabular}

Sources:

(1) https://www.statistics.com/statistics/1110879/coronavirus-cumulative-cases-in-nigeria

(2) Authors' computation

Table1 shows that the number of confirmed cases increased cumulatively every month rising from one in March 3 to 81, 963 in December 25 and further to 126,160 in January 27,2021. The monthly increase was gradual but reached the peak in July 31 with 17, 457 and thereafter declined to 10,857 in August and further declined in September and October, but began to rise from November till date. The highest monthly percentage increase was recorded in March 31 with 13,400 and thereafter began to decline drastically and picked up again from November. This is regarded as second wave which has the tendency of repeating the initial impact on the socio-economy of Nigeria.

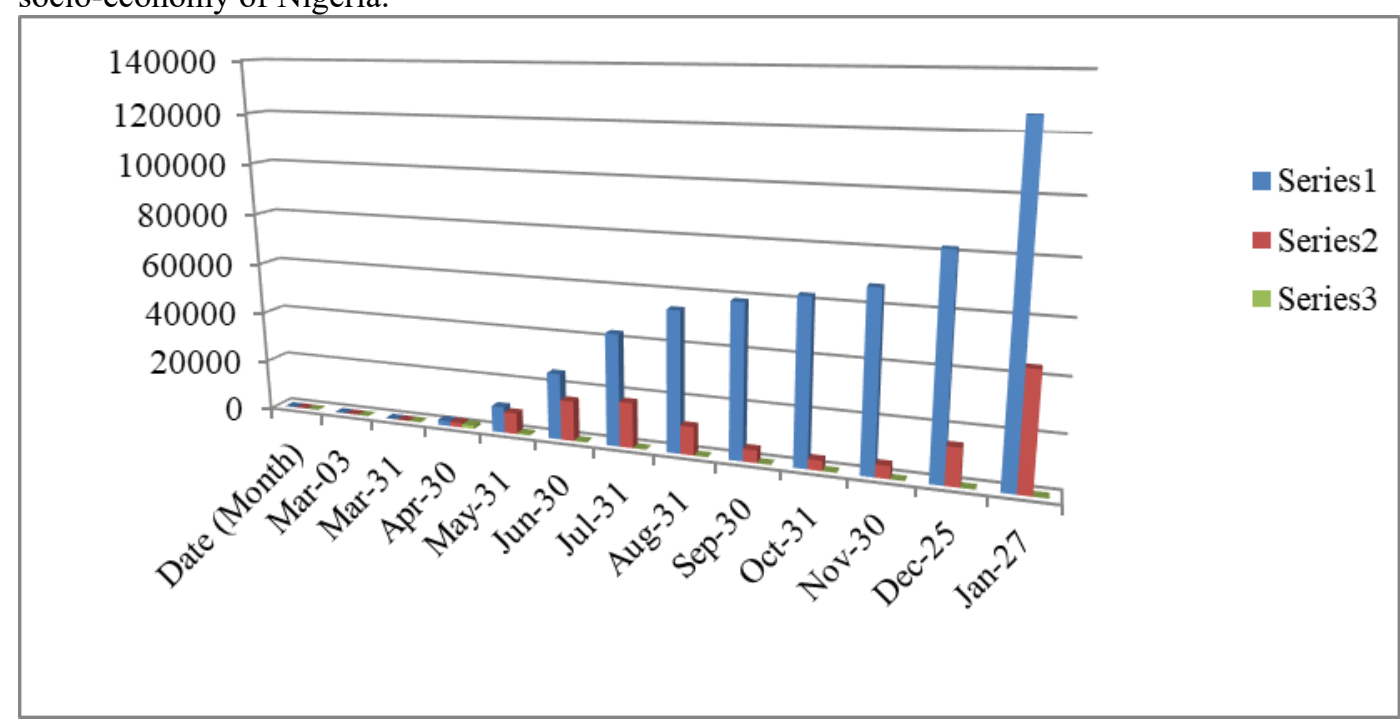

Fig 1: Bar chart showing Number of COVID-19 confirmed cases, Monthly increase in confirmed cases and Percentage increase.

The figure shows that the confirmed cases continue to increase though it started gradually from March to April till date. The monthly increase became much noticeable from May and reached the highest point in July and thereafter began to decline and then significantly increased from December 2020 till date e due to the effect of the second wave. The highest monthly increase occurred between March 3 and March 31, 2020 and then declined in July but picked up in November till date. 


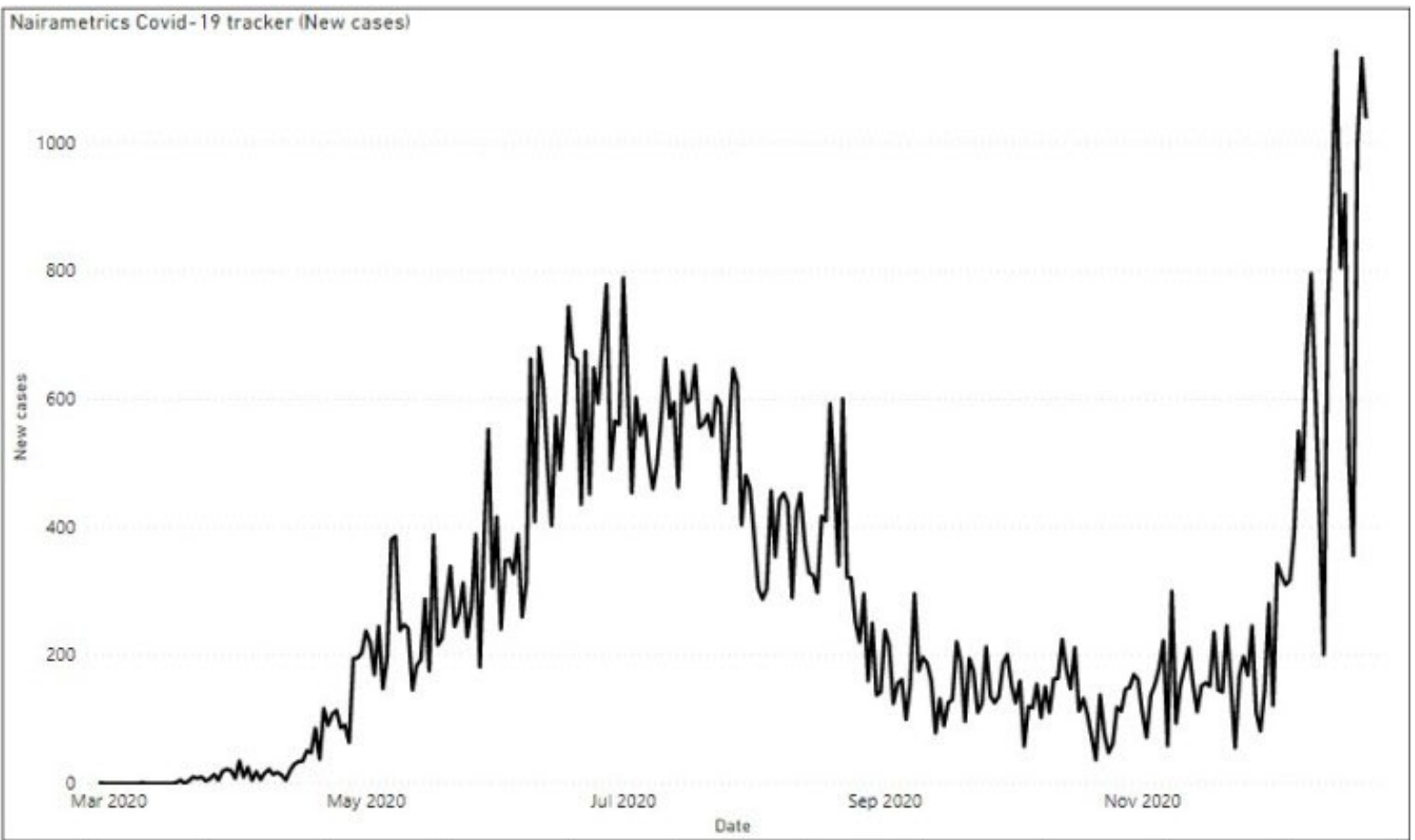

Source: Nairametrics.com (25 ${ }^{\text {th }}$ December, 2020). https://nairametrics.com/2020/12/25/covid-19-update-innigeria

Fig. 2: Trend of COVID-19 confirmed cases in Nigeria.

Fig 2 shows gradual increase in confirmed cases of COVID-19. The figure shows increase from March to April and declined for a short period and began to rise oscillatory in May till July when it reached the peak and fell down in the same manner till mid-November from where it began to rise again till date. The flattening curve encouraged gradual reopening of the economy and schools but the recent increase is leading to partial economic lockdown.

\section{Impact on Nigeria Socio-Economic Development}

COVID-19 pandemic has holistic effects on health, economy, education, social services and all-round development at individual, communities, nations and global level. The impact could vary in different countries and sectors. Scholars, researchers, journalists, organisations and agencies/commissions have written on socioeconomic impact of COVID-19 in Nigeria and around the globe. A study by Ajibo (2020) found that COVID-19 pandemic has had a devastating impact on the economic well-being of Nigerians. Health is key to a prosperous productive society. Fourie (2020) describes unhealthy as illness that can stifle production, consumption recreation and well-being. Unhealthy socio-economic is disastrous to any development nation as it brings underdevelopment. Besides, the Nigerian health system was ill equipped and underprepared to handle the COVID-19 pandemic and hence testing and treatment of the disease posed a challenge to many Nigerians. Only a total of $1,270,523$ tests have been carried out which represents $0.64 \%$ of the total population (200 million). No doubt, this figure (percentage) is statistically too low to predict the rate of spread of the disease among people living in Nigeria.

African Union (2020) describes the impact of COVID-19 pandemic as plunging the world economy to depths unknown since the Second World War, contributing to the woes of an economy that was already struggling to recover from the pre-2008 Crisis. This pandemic is disrupting an inter connected world economy through global trade, abrupt falls in commodity prices, fiscal revenue, foreign exchange receipts, foreign financial flows, travel restrictions declining of tourism and hotels e.t.c. According to International Monetary Fund (2020) in Africa, the pandemic has already plunged 8 Africa States into recession. Meanwhile, Nigeria had been grappling with weak recovery from the 2014 oil prince shock with GDP growth tapering around 2.3 per cent in 2019. The COVID-19 pandemic in Nigeria has increased the level of tension and anxiety among citizens and government.

According to African Union (2020) the openness of the continent to international trade and migration, makes it vulnerable to the harmful effects of COVID-19, which are of two kinds: endogenous and exogenous.

"The endogenous effects occur as a result of the rapid spread of the virus in many African countries. On one hand, they are linked to morbidity and mortality. On the other hand, they lead to a disruption of economic activities. This may cause a decrease in domestic demand in tax revenue due to the loss of oil and commodity 
prices coupled with an increase in public expenditure to safeguard human health and support economic activities.

The exogenous effects come from direct trade links between affected partner continents such as Asia, Europe and the United States; tourism; the decline in remittances from African Diaspora; Foreign Direct Investment and Official Development Assistance; illicit financing flows and domestic financial market tightening, etc.". pg 5.

Nigeria being an African country is not immune to both exogenous and endogenous effects of the coronavirus infection. Nigeria has a share of tragic health hazards and human consequences recorded globally. It has accounted for 2,186,749 deaths in over 196 countries. 164 deaths were recorded in Nigeria as at May 13th, 2020 and by November 19th, 2020 the figure rose to 1,165 and further to 1,544 in January 27, 2021 (Nigeria Centre for Diseases Control).

Decline in oil price was a major effect of COVID-19 pandemic. The price of crude oil declined drastically as a result of low demand, the price of crude oil dropped from initial US $\$ 60$ per barrel to as low as US $\$ 30$ in April 2020 and consequently the revenue of government from crude oil reduced. Also, aviation fuel and automobile fuel were affected as a result of ban in international travels and restrictions in local travels within the country. The resultant effect of this decline is the inability of government to meet with fiscal budget for the year. The national budget was affected based on initial projection from crude oil bench mark of US \$57 per barrel. This led to reduction in budgetary appropriations to Ministries, Agencies and Departments (MDAs) from the 2020 fiscal year. Invariably, it led to low supply of funds to the economy resulting in major macro-economic effects.

Stanley, Nkporbu and Stanley (2020) found a high level of fear and apprehension associated with the Covid-19 Pandemic among the general public occasioned by huge National, State as well as individual socioeconomic loss and difficulties due to the lockdown and restrictions including markets, shops and other private and public businesses. As a result, many especially those on small and middle cadre employments have lost their jobs, there increased dependency, hunger, sufferings and has posed a lot of restiveness and social insecurity.

One of the painful effects of COVID-19 is job loss. Many people have lost their jobs mostly people in private sector due to economic reality as a result of COVID-19 pandemic. A survey study found that $42 \%$ of the overall job loss could be traced directly to COVID-19, with a higher percentage of loss employment among the poorest (49\%) and urban (48\%) households, relative to the wealthiest (39\%) and rural households (38\%).

Decline in borrowers' capacity to service loan deprived banks to soundness and stability in earnings. Borrowers also struggled to repay the loan granted to them before the pandemic outbreak. In the same vein, daily income earners found it extremely difficult to continue to struggle for income to survive. The poor faced economic hardship of surviving the COVID-19 lockdown and restrictions.

The lockdown measure had effects on productive and supply chain in the economy. Andam, Edah, Oboh, Pauw and Thurlow (2020) findings on the impact of COVID-19 on food indicate that total GDP fell 23\% during the lockdown. Agric-food system GDP fell $11 \%$, primarily due to restrictions on food services. Household incomes also fell by a quarter, leading to $9 \%$ points increase in the national poverty rate. Given the scale of these economic losses, the recovery scenarios indicate that, even with a rapid easing of restrictions and global recovery, Nigeria is unlikely to escape a deep economic recession. The current inflation (12.82\%) in goods and services is possible reflection of the study's conclusion. Furthermore, Adeyemo (2020) stated that the impact of the pandemic on food systems could be direct or indirect but both manifesting through modification of food supply and demand dynamics of the economy. The pandemic has the tendency to worsen a weak food supply system through reduction in domestic agricultural production and a restriction in the global food supply. Ibrahim (2020) study of COVID-19 lockdown and transitory food insecurity in Nigeria found that the more the stressful number of lockdown days and inter-states-countries movement restrictions the more it severely affect the level of economic (food prices increase, rise in transportation cost, hoardings by marketers, increase in post-harvest loss at both farm and market levels, low purchasing power by household, etc.) with adverse effect on food security.

Nigeria import-dependent problem led to reduction in flow of goods into the country during the global spread of the pandemic. Importation of goods from China was put on hold as a result of COVID-19 where all foreign companies and factories were short down which affected supplies of products such as pharmaceutical, automobile spare parts other finished goods that were put to hold as a result of border closure.

Insecurity became the major problem as COVID-19 continues to impact on Nigerians. Most people who earned daily income could not meet their basic needs as result of Government preventive measures to reduce the spread of COVID-19. These measures (Lockdown order) prompted some category of people to attack other (people) in their respective houses with the hope of looting their resources in other to survive. For instance, the one million boys terrorized Lagos, Ogun and Oyo States while there were other attacks in other part of the country.

Just like other sectors of the economy, education has its share of the effects of COVID-19. The pandemic has potential risk to the health and safety of learners, teachers, education practitioners, school administrators, parents and the community in general. According to Federal Ministry of Education (FME, 2020) more than 1.5 
billion children and young people globally have been affected by closure of schools and universities. Schools and facilities have been closed in Nigeria since late March 2020 and close to six months leading to learning loss, possible expansion of inequalities, learning crisis and greater exposure of the most vulnerable children to risk of exploitation. Furthermore, the economic pressures and negative impact of school closures on girls, children with disabilities, without access to family support networks or online or other distance learning platforms limit their access to their fundamental rights to safe and inclusive education.

The Federal Ministry of Education stated that an estimated 80 million children, youth, and adult learners in the system are deprived access to schools and have very limited alternative learning opportunities for over threemonths period at the minimum. The closure of schools and learning facilities during the pandemic will also result in further deterioration in facilities and capacities for the delivery of quality education. It has altered academic sessions, academic related programmes such as National Youth Service Corps among others. Besides, when schools resume, the pandemic's health risk to learners and teachers may be very high and devastating without adequate and effective risk-mitigation measures.

\section{Education Sector response to COVID-19 in Nigeria}

Researchers have discovered vaccines and drugs to cure COVID-19 but before these are produced and distributed in sufficient quantities around the world, prevention serves as the main measures to minimise the transmission of the deadly virus among people. Besides, many sectors have evolved different measures to respond to COVID-19 and education is not an exception. In this regard, the Federal Ministry of Education (FME) in consultation with the Nigeria Centre for Disease Control (NCDC), the Presidential Task Force (PTF) on COVID-19, and stakeholders developed guidelines for school re-opening in Nigeria. Major highlights of the guidelines are discussed in this section.

\section{Staying at home and learning safely}

One of the strategies employed to reduce the spread of COVID-19 is staying at home and learning safely. Governments (Federal, State, and Local) had the responsibility of ensuring learners are "safe to learn at home" irrespective of their locations, access to internet, and socio-economic background. This responsibility includes sharing public health messages about COVID-19, including its symptoms, how it is transmitted, and how to prevent transmission. Furthermore, the impact of COVID-19 means that more learners are online, which leaves them vulnerable to risky online behaviour, cyber-bullying, sexual exploitation, and other cyber threats. To reduce this risk, it was recommended that, for children, continuous child-friendly messaging using info graphics, cartoons, animations, and so on that show how to protect them should also be available in their learning packages.

Actions recommended in respect of safeguarding the health, safety, and security of learners accessing remote learning include:

FME, TETFund, SMoE, UBEC /SUBEBs, Federal Ministry of Communications and Digital Economy, NTI, TRCN, NERDC, NMEC, SAME were charged with the responsibility of providing online training that not only prepares teachers to teach in a way that safeguards the health, safety, and security of the learners but also enables to facilitate learning using twenty-first century pedagogy based on ICT.

To support the training, FME, TETFund, SMoE, UBEC, SUBEB, SAME, NMEC were meant to provide learners with printed materials, online learning, radio, or TV programmes.

Parents, guardians, caregivers, and communities were to ensure children and young people stay at home and wash their hands regularly, maintain personal hygiene and adhere to WHO/NCDC COVID-19 guidelines.

\section{Before schools and learning facilities reopened}

In line with the Federal Ministry of Education guidelines on school reopening, the reopening timing was guided by the best interest of learners and overall public health considerations based on an assessment of the associated benefits and risks, and socio-economic factors. The Federal and State governments were guided by recommendations, advice, or directives from the World Health Organization (WHO), Federal Ministry of Health $(\mathrm{FMoH})$, and Nigeria Centre for Disease Control (NCDC) for effective risk avoidance and mitigation of the effect of COVID-19. Decision making involved all major stakeholders, including government at all levels, communities, and the civil society so as to ensure that decisions and planned actions are based on comprehensive analysis, consensus, and adequate consideration for context. Furthermore, the Federal and State Ministries of Education (SMoE) decided when to reopen schools after due consultations with the Presidential Taskforce on COVID-19 (PTF) and other critical stakeholders, including parents/ guardians, teachers' unions, communities, education service providers, PTA, and School-Based Management Committees (SBMCs).

\section{Social Distancing}

In schools and other learning facilities, learners required to be supported to stay two meters apart. Classrooms, 
dining halls, staff rooms and offices required having sufficient space to allow for two-meter separation between all individuals. It suggested that in situations such as early years, younger primary school children, and those with additional needs, where the two-meter rule could not be reasonably applied and other risk mitigation strategies may be adopted. In these circumstances, risk assessments must be undertaken with the best interests of the learners, teachers, and other education personnel in mind. The scenarios require organizing learners and children into small groups with consistent membership and compliance to the risk mitigation strategies.

\section{Alternative Learning Modules for Safe Distancing}

As schools and learning facilities reopen, they must implement safe distancing measures that minimize and isolate risk-taking cognisance of learners that require additional support or have disabilities that are disadvantaged. These alternative models that focus on flexibility in scheduling and content delivering include:

Staggered attendance: Learners may arrive and depart at different times to avoid overcrowding; schools may reopen gradually (e.g., starting with particular grade levels).

Alternate attendance: Schools may alternate attendance days per week, with learners at the secondary level (or equivalent) and above having fewer in-person classes, since these learners can better manage independent learning (e.g., junior secondary school learners attend on Tuesdays and Thursdays while primary school learners attend classes on Mondays, Wednesdays, and Fridays)

Platooning: Classes may be divided into morning and afternoon shifts.

Outdoor learning: This can limit transmission and also allows for safe distancing between learners and teachers. The use of shelter outdoors is necessary for the protection and safety of learners and teachers. In addition, safety in all weathers and security measures are required for each location.

Flexible schedule: Lessons may be structured in a way that reduces the need for learners and staff to move between the different areas of the premises.

Decreased interaction: Learners may remain in one location with teachers coming to them.

Creative delivery: Lessons may be delivered more holistically to take into account various learning environments for in-person learning (indoor, outdoor) and various media for distance learning (printed materials, online, TV, and radio). Learners may have allocated time learning in each of these environments to reduce the burden placed on indoor facilities.

\section{Close, Partially Close, or Reopen Considerations}

The following steps and actions are expected to be taken before schools and learning facilities are reopened to safeguard health and ensure safety and security of learners, teachers, administrators, and other education personnel. These steps and actions fall within policy, sensitisation, safety and hygiene, financing, build back better, learning and monitoring.

Policy: FME, PTF, FMoH (NCDC), FME, NUC, SMoEs, NHRC, NMEC, SAME, EIEWGN, UBEC, and SUBEBs including other relevant stakeholders were required among others to:

Review existing policies, practices, and risk mitigation strategies in the use of schools for other purposes, such as distance learning centres, temporary shelters, isolation, quarantine and treatment centres, markets, voting centres, etc.

Provide national policy, guidelines, and parameters for decision making and actions on safe school opening with roles and responsibilities of all stakeholders clearly outlined.

Clarify and communicate policies, strategies, and actions to ensure safe school reopening and continued safe operation such as:

Education in Emergencies (EiE) Sector Plans;

Back-to-school strategies, e.g., social distancing; readjustment of academic year calendar and school opening hours;

use of double shifts;

provision of Personal Protective Equipment (PPE);

use of $\mathrm{n}$ thermometers;

WASH facilities in schools;

staggered use of school facilities to ensure compliance with NCDC guidelines; and

development and dissemination of Safe School Reopening Checklist to assist appropriate evidence-based decisions to reopen schools.

Sensitisation: FME, NOA, SMoE, FMOH, SUBEBs, NMEC, SAME, FMIC, SMoIs with the support of other relevant stakeholders carry out Sustained campaigns, advocacy and sensitization, especially in rural and remote areas and child/girl-friendly messaging (using animations, infographics and cartoons in local languages) on the pandemic and public health and safety measures to be adopted to promote necessary behavioural changes.

Safety and Hygiene: FME, FMoH (NCDC), SMoH, Ministry of Water Resources, FMoEnv, school administrators, SMoEnv, UBEC, NMEC, SUBEBs, SAME, private school owners with the support of 
stakeholders carry out the following actions:

Disinfection and fumigation of facilities, including hostel accommodation (if available); particular attention given to those used as temporary isolation and treatment centres and for other purposes during the pandemic;

Ensure a School COVID-19 Referral System, including protocols and procedures to take if learners, teachers, administrators, and other education personnel become unwell while in schools;

Develop detailed protocols and provide facilities and measures for the maintenance of two-meter safe distancing to comply with NCDC guideline;

Develop detailed protocols and provide facilities to establish and maintain prescribed hygiene standards and practices, including WASH, hand washing, access to adequate gender-segregated toilet facilities, crossventilation of class rooms and hostel accommodation, use of face masks, proper food preparation and handling as well as disposal of wastes;

Sensitize, train, and build capacity of teachers, administrators, and other education personnel to effectively use and comply with the School COVID-19 Referral System and protocols for safe distancing and hygiene in schools; and

Set up school hygiene committees with designated hygiene champion to monitor and promote compliance.

Financing: PTF, FME, NUC, UBEC, SMoE, NMEC, SAME, SUBEBs, NTI, TRCN, NERDC conduct a rapid assessment and determine funding requirement for upgrading infrastructure and facilities (such as classrooms, furniture, WASH, and ICT facilities) to meet and sustain prescribed safe school reopening requirements.

Build Back Better: FME, SMoE, FMoH, SMoH, TETFund, UBEC, NUC, SUBEBs, NMEC, SAME, Federal Ministry of Power, REA with the support of stakeholders mobilize and deploy new and existing resources to: Recruit additional teachers and education personnel to guarantee prescribed safe distancing teacher-learner ratio; Equip and resource schools for improved teaching and learning methods for special needs learners;

Provide WASH facilities including soap, hand sanitizers, and girls' dignity kits in schools;

Establish and adequately equip dispensaries and clinics as appropriate;

Create adequate classrooms and learning spaces to maintain safe distancing in schools;

Provide better ventilated classrooms and TLCs; and

Use solar power and alternative energy sources for electricity, and boreholes for water.

Learning: FME, SMoE, TETFund, Federal Ministry of Communications and Digital Economy, NMEC, UBEC, NUC, SUBEBs, NTI, SAME,TRCN, NERDC with the support of relevant stakeholders conduct training and capacity development for teachers and administrators to enhance their competence in effectively delivering and facilitating safe online and remote teaching and learning and their ability to provide psychosocial support.

Monitoring: FME, FMoH (NCDC), SMoH, Ministry of Water Resources, FMoEnv, SMEnv, SMoE, UBEC, NMEC, SAME, SUBEBs, EHOs with the support of stakeholders establish monitoring and evaluation framework, monitoring teams, tools, and schedules to track and report progress on safe reopening and operations.

In addition to the guidelines, the Northern States Commissioners of Education resolved among others to implement the followings towards school reopening:

States invest in building the administrative capacity of principals and teachers through workshops and supporting school administrators and teachers to attend courses in institutes of education and public administration;

Inclusion of Information Communication and Technology in school administration to equip school principals and teachers with relevant skills to deliver quality education; and

Engage the Universal Basic Education Commission (UBEC) and the support of relevant stakeholders in developing the needed strategies for integrating children of all Almajiri schools into the formal education system. Tertiary institutions: the summary of extract from tertiary institutions regulatory agencies (National Universities Commission, National Board for Technical Education and National Commission for Colleges of Education) to institution heads on re-opening of schools directed that schools should continue to adhere to safety protocols and the Nigeria Centre for Disease Control (NCDC) guidelines which is very much in force. It further stressed that the decision to re-open institutions should not, in any way, diminish the importance attached to full compliance as COVID-19 is still much in force. Institutions are to be monitored by the staff of the regulatory agencies and Federal Ministry of Education for on-the-sport inspections and verifications of physical facilities like the lecture theatres, classrooms, staff offices, laboratories, student accommodations, emergency services/capability, healthcare buildings and the deployment of non-pharmaceutical measures which are germane to institution state of preparedness for the resumption of academic activities and in compliance with quality assurance/safety standards.

\section{Extent of compliance with the school re-opening guidelines}

States were at varying level of compliance with the guidelines for school re-opening. Meetings with the stakeholders by Federal Ministry of Education to decide the re-opening were held and agreement reached taking into consideration the guidelines visa-visa the safety protocols and safety measures. This was replicated at state 
level and the outcomes determined the resumption time and methods adopted. Thus, plans to make some schools resume early were stalled by the inability of many schools to meet up with safety demands and guidelines. Similarly, Onyeyi and Adebowale (2020) stated that the inability of schools to meet up with safety demands accounted for the Nigerian government to initially resolve not to allow candidates in the country to sit for WAEC. However, after a due consideration Nigeria joined Ghana, Sierra-Leone, The Gambia and Liberia to write the examinations which commenced in August 17, 2020. During the examinations, some students in Bayelsa and Akwa-Ibom tested positive to COVID-19 which confirmed the initial fear of Nigeria government. Also, the response strategy of the federal and states was not sync. The reopening of secondary and primary schools is the responsibility of states except Federal Unity Colleges (FUCs) in which the federal government has oversight function.

At the start of reopening schools, only students and pupils in exit classes namely Primary 6, JSS3 and SSS3 were allowed to resume on August 4 to prepare for their terminal examinations. This conforms to staggering reopening recommended in the guidelines. However, Benue state fully reopened schools for all classes which is a breach of the guideline while many states did not. Expectedly, the Federal Ministry of Education took lead in reopening of schools. According to Odutola (2020), the Federal government directed unity schools to reopen by October 12 after due consultations and exhaustive discussions with the relevant stakeholders and development partners. Private schools were directed to work out their modalities for reopening. This again indicates compliance with the guidelines.

The tertiary institutions regulatory agencies mandated institutional heads to comply with federal government and NCDC guidelines on school reopening and safety protocols on COVID-19 pandemic prevention. Institutions that were set to reopen were checked by the staff of the regulatory agencies and Federal Ministry of Education for on-the-spot inspection and verifications of physical facilities like the lecture theatres, classrooms, staff offices, laboratories, student accommodations, emergency services/capability, healthcare buildings and the deployment of non-pharmaceutical measures which are germane to institution state of preparedness for the resumption of academic activities and in compliance with quality assurance/safety standards.

UNICEF in collaboration with the Federal Ministry of Education disseminated guidelines on safe school reopening and also trained School Based Management Committee (SBMC) members (Muntaka, 2020). This was in recognition of the roles SBMCs play in school development including access and participation. In addition to SBMCs, all chairmen of Centre-Based Management Committees (CBMCs) in 44 Local Government Areas in Kano State were trained and worked with other stakeholders at the community level to comply with the guidelines on re-opening of schools. Hayyod (2020) reiterated that UNICEF provided the support for reopening of schools to allay the fears parents were nursing about sending their children back to school because of the effects of COVID-19.

According to Ogu (2020), the SBMC awareness led to proactive Mothers' Association, a sub-committee of SBMC in Gwale Local government in purchase of 200 buckets, soaps, hands sanitisers, 2,300 face masks, first aid drugs and writing materials which were distributed in schools. The association also engaged mothers in house-to-house campaigns on resumption of schools to sensitise mothers to send their children to back to school. Furthermore, the SBMC disinfected school compounds by fumigation and cut overgrown grasses as well as made preparations to replace damaged roofs of classrooms, among others.

Findings of survey of level of compliance with COVID-19 guidelines for reopening of schools in the six geo-political zones indicate the followings:

Lagos State, restrictions were placed by the ministry of education particularly government owned schools on principals commenting on level of school compliance with COVID-19 safety protocols, however, there were hand washing equipment and hand sanitisers in various in various schools though temperature checks were missing. Students maintained physical distancing in the examination halls as they were spread in many classrooms to achieve COVID-19 compliance in sitting arrangements.

In Borno State, government provided the COVID-19 safety measures items such as hand washing facilities, hand sanitisers and face masks but such provision was supported by spirited individuals and Non-Governmental Organisations (NGOs) and School Based Management Committee (SBMC). Sustainability of sanitisers has been regarded as inadequate because they are exhaustible items.

Abuja, the exam classes reopened as others with all COVID-19 safety measures put in place and ensured physical distancing in classrooms. Other levels of school reopened much later and in compliance with the federal government COVID-19 directive. Isolation centres were in place in many schools in case of any COVID-19 challenge.

Ebonyi State, government distributed hand washing materials, soap, hand sanitisers and ensured physical distancing in sitting arrangements. The challenge of non-replacement of exhaustible items such as soap, hand sanitisers exists.

Kaduna State, government provided COVID-19 safety measures in public schools in compliance with COVID-19 protocols. These include water containers for hand washing, soap, sanitisers and face masks. Social 
distance was observed by teachers and students. Private schools also complied with the safety demands.

Akwa-Ibom State, safety measures such as hand washing, soap, sanitisers, non-contact temperature checks and use of face masks to some extent were in use in both public and private schools. Students keeping social distance protocol were not observed to a large extent while some schools were yet to have the basic safety measures requirement.

\section{Conclusion and Recommendations}

COVID-19 disease broke out in December 2019 in Wuham, China. It was then thought that the disease was one of the viral diseases affecting China hence "China disease" and little did any know that it soon become a global disease (pandemic) that would shake the entire world. The spread began in March after the first index case and was also thought to be southern Nigeria problem but soon it cut across the country though with varying degree of prevalence. The impact was felt in sectors of the economy including education which experienced about six months closure of schools. Measures to curtail the spread of the disease include lockdown, boarder closure, restrictions on internal and international travels, closure of schools and public places such as churches and mosques, eateries, among others. These generally affected the socio-economic development of the country. The education sector response to COVID-19 involved development of guidelines for reopening of schools which was led by FME in collaboration with NCDC and development partners. Schools have resumed and findings indicate that many schools complied with the guidelines while others partially did. Besides, sustainability of provision of exhaustible safety measure items poses a challenge coupled with relaxing attitude to COVID-19 protocols whereas there are incidences of break out of the disease in some schools as the second wave is spreading faster.. In view of the foregoing, the paper recommends that awareness programme for school heads, parents and SBMCs should continue while the school heads in turn continue such in their schools. Government through ministry of education needs to continue provision of basic safety measure requirements particularly the easily exhaustible such as soap, hand sanitisers, etc. It is also important for quality assurers to monitor the schools regularly to ensure compliance with school reopening guidelines. Government also needs to rehabilitate classrooms and provide more furniture to aid social distancing in classes and as well provide portable water to schools to solve the problem of getting water for hand washing and hygiene. Further, parents and SBMCs should be encouraged by school heads and educational administrators to support schools in provision of basic requirements for safety measures among others. The staff of FME and tertiary institutions regulatory agencies should periodically inspect tertiary institutions (public and private) to ensure compliance with the guidelines. Ministries of education and State Universal Education Boards as well as relevant agencies need to build capacity of education administrators, managers, planners and teachers on digital learning and provide digital infrastructures for online teaching and learning. This will enable learning to take place regardless of health and social challenges or emergencies. Teaching through electronic media should continue to complement the face-toface teaching. Tertiary institutions should strengthen the virtual and e-learning modes while a quality check mechanism is put in place to quality assure education delivery.

\section{References}

Abe, O. (2020). The National Commission for Colleges of Education (NCCE) has released new directives to Provosts of Nigerian Colleges of Education for the safe reopening of their schools for academic activities during the COVID-19 pandemic. Campus Reporter.https://campusreporter.ng/ncce-issues-directives-toprovosts-for-reopening- of-colleges-of-education. October 17, 2020. Retrieved 17 November, 2020

Adeyemo, T. A. (2020). Food insecurity: The real menace of COVID-19 in Nigeria. [Online Available:https://niser.gov.ng

Africa Union (2020). Impact of the coronavirus (covid-19) on the African Economy. [Online]. Available: https://www.tralac.org/documents/resources/covid-19/3218-impact-of-the-coronavirus-covid-19-on-theafrican-economy-african-union-report-april-2020/file.html

Ajibo, H. (2020). Effect of Covid-19 on Nigerian Socio-economic Well-being, Health Sector Pandemic Preparedness and the Role of Nigerian Social Workers in the War Against Covid-19. Social Work in Public Health. 35, 511-522. https:/www.tandfonline.com/doi/abs/10.1080/19371918.2020. Retrieved 27 October, 2020

Andam, K; Edeh, H; Oboh, V; Pauw, K \&Thurlow, J. (2020). "Impacts of Covid-19 on food systems and poverty in Nigeria. Advances in Food Security and sustainability". Elsevier Public Health Emergency Collection. 5: 145-173. https://www.,cbi.nlm.gov/pmc/articles/PMC7550085 . Retrieved 17 November, 2020

Auwal, M. M; Shehu, S and Galadima, B. D. (2020). 2019 Novel Coronavirus (COVID-19) Outbreak Nigeria and Preparedness for African Countries: A review of the Current Literature.

Bongaarts, J; Pelletier, F \& Gerland, P. (2009). "Global trends in AIDS mortality, Poverty, Gender andYouth". Working paper no. 16. New York: Population Council. Version of record. https://doi.org/10.1007-90-481- 
9996-8 Retrieved 16 April, 2020

Center for system science and Engineering (CSSE) (2020). Global cases of Covid-19. Johns Hopkins University. Johns Hopkins CSSE. https://www.rfp.org/resources/coronavirus-covid-19-global-cases-by-the-center-forsystems-science-and-engineering-csse-at-johns-hopkins-university-jhu. Retrieved 16 April, 2020.

Akanni, L. O and Gabriel, S. C. (2020). The Implication of Covid-19 Pandemic on the Nigeria Economy. Centre for the study of the Economics of Africa. http://cseaafrica.org/the-implication-of-covid19-on-the-nigerianeconomy. Retrieved 20 November, 2020

European Centre for Disease Prevention and Control. (2020). Risk assessment: Outbreak of acute respiratory syndrome associated with a novel coronavirus. https://www.eurekalert.org/pub_releases/2020-01/ecfdooa012620.php. Retrieved 20 November, 2020

Federal Ministry of Education (2020). Guidelines for schools and learning facilities reopening after COVID-19 pandemic closures. Abuja. Federal Ministry of Education.

Fourie, J. (2020). Beyond 2020: a vision of a prosperous South Africa economy: opinion. Finweek 2020 (16 January) 144.

Hassan, A.H.(2020). "Coronavirus (COVID-19): Current Situation in Nigeria”. Journal of On-goingChemical Research. , 5(1): 32-34, Document ID: 2020JOCR43, doi

Henderson, D.A. (2009). Smallpox: The Death of a Disease - The inside story of eradicating a Worldwide killer. Prometheus Books.

Ibrahim, M. A. (2020). "Covid-19 lockdown and transitory food insecurity in Nigeria. Food and Agribusiness Management”. Zibeline International Publishing. 1(1) 26-30. DOI: 10.26480/fabm.01.2020.26.30

Ian, M. (2020). Nigerian Private Sector Supporting Government Efforts to Fight COVID- 19. Gbc health News, March 2020. http://gbchealth.org/nigerian-private-sector- supporting-government-efforts-to-fight-Covid-19 . Retrieved 16 May, 2020

Ochamann, S. \& Roser, M. (2012). Smallpox. https://ourworldindata.org/smallpox. Retrieved 17 November, 2020

Odutola, A. (2020). FG directs schools to fully reopen on October 12. Nairametric. October 2, 2020.

Ogu, E. (2020). In Northwest Nigeria, communities prepare for reopening of schools shutdown by COVID-19. https://www.unicef.org/nigeria/stories/northwest-covid-19- communities-prepare-re-opening-schoolsshutdown-covid-19. Retrieved 17 November, 2020

Osagie, E. (2020). Minister of Health report during presidential task force on coronavirus disease briefing in Fct Abuja ,15 ${ }^{\text {th }}$ April 2020. https://allafrica.com/stories/202004020070.html, Retrieved 17 November, 2020

Oyeji, E \& Adebowale, N. (2020). Premium Times. COVID-19: Ahead of full resumption, many schools yet to put adequate safety measures in place. https:/www.premiunmtimesng.com/coronavirus/416345-covid-19ahead-of-full- resumption-many-schools-yet-to-put-adequate-adequate-safety-measures-in-place.html Retrieved 17 November, 2020

Oyekanmi, S. (2020). Covid-19 update in Nigeria. Nairametrics. https://nairametrics.com/2020/11/17/covid-19update-in-nigeria Retrieved 25 December, 2020

Ozili, Peterson, K. (2020). "Covid-19 pandemic and economic crisis the Nigerian experience and structural causes". Journal of economic and Administrative Sciences. DOI: 10.1108/JEAS-05-20200074.https://www.researchgate.net/publication/346010930_COVID-

19 pandemic_and_economic_crisis_the_Nigerian_experience_and_structural_causes. Retrieved 20 November, 2020

Stanley, C. N., Nkporbu, A. K. \& Stanley P. C. (2020). "Socio-Economic Implications of the Coronavirus Pandemic: Early Review and Projections, Nigeria in Focus". International Journal of Research Studies in Medical and Health Sciences Volume 5, Issue 4, 2020, PP 40-49. http://www.ijrsmhs.com/pdf/v5-i4/10.pdf . Retrieved 18 November, 2020

The Guardian 20 September, 2020. Northern states may reopen schools before Oct. 30 - Commissioners. https:/guardian.ng/news/northern-states-may-reopen-schools- before- Oct-30-commissioners. Retrieved 19 November, 2020

Van D, N. \& Morris, D, B, T. (2020). "Aerosol and surface stability of SARS- Cov2 as compared with SARSCov-1”. New Engl J Med. 2020.doi: 10.1056/NEJMC2004973.

Wikipedia-Coronovarius disease (2019). https://end.m.Wikipedia.org./coronavirus- disease2019, Retrieved 7 November, 2020

World Health Organization (2020). Director General opening remarks at media briefing on COVID-19, 11 March, 2020. https:www.cdc.gov/coronavirus/2019ncov/about/index.html Retrieved 12 April, 2020.

World Health Organization (2019). Situational report on Coronavirus. 2019 COVID-19. https:/home.kpmg/ng/end/home/insights/2020/03/covid-19.

World Health Organisation (2020). COVID-19 Dashboard. https://covid19.who.int/?gclid Retrieved 18 Nov. 20 